\author{
Military Technical College \\ Kobry El-Kobbah, \\ Cairo, Egypt.
}

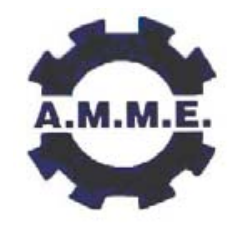

$13^{\text {th }}$ International Conference on Applied Mechanics and Mechanical Engineering.

\title{
SIMULATION OF COMPRESSION ENGINE RUNNING ON DIFFERENT TYPES OF FUELS
}

\author{
HAMDAN $^{*}$ M. A.
}

\begin{abstract}
The present work describes a theoretical investigation concerning the performance of a four strokes compression engine, which is powered by alternative fuels in the form of diesel-ethanol and diesel -ether mixtures, the properties of which were sited from literature. The amount of each alcohol added was 5, 10 and $15 \%$ by volume. The engine speed during the experimental work was within the range from 1000 to 4000 rpm, with engine was set at full throttle opening and hence the engine was operating under full load conditions. Several parameters were calculated namely; engine torque, brake mean effective pressure, brake power, specific fuel consumption and the thermal efficiency, this was carried out using DIESEL-RK Software.

It was found that the engine is of highest thermal efficiency when it is powered by a 15 $\%$ ethanol-diesel blend, wile it is of minimum thermal efficiency when it is powered by pure diesel fuel.. Further, it was found that both the thermal efficiency of the engine and the specific fuel consumption increases with the percentage of either ethanol or ether in the fuel blend. However, the power was found to decrease with the amount of either ethanol or ether in the fuel blends.
\end{abstract}

\section{KEY WORDS}

Alternative fuel ; Diesel engine; ethanol-diesel blend, ether-diesel blend

* Professor of Mechanical Engineering, Dept. of Mechanical Engineering. Faculty of Engineering and technology. University of Jordan. Email: mhamdan@ju.edu.jo 


\section{INTRODUCTION}

It is well known that transport is almost totally dependent on fossil, particularly, petroleum-based fuels such as gasoline, diesel fuel, liquefied petroleum gas (LPG) and natural gas (NG). In the last years, the world has been confronted with an energy crisis. The most used fuel, petroleum, is becoming scarce and its use is associated with the increase of environmental problems. Experts suggest that current oil and gas reserves would suffice to last only a few more decades. To exceed the rising energy demand and reducing petroleum reserves, fuels such as biofuel are in the forefront of the alternative technologies. Typical biofuels are biodiesel and alcohol.

The importance of biodiesel has been pointed out in recent works [1-7], and it is a very interesting alternative fuel to the diesel. The Biodiesel can be obtained from renewable sources, such as vegetable oils or animal fats, through a transesterification process. This comes from the fact that in order to use vegetable oil in a diesel cycle engine without needing adaptations in the motor, it is necessary to submit this oil to a chemical reaction denominated transesterification, where the main objective is to reduce the oil viscosity to a value close to that of the diesel.

Among the many advantages of the use of the biodiesel are the great renewability and biodegradability, that it presents good lubricity and it contains very small amounts of sulfur. Not to mention that it has a higher flash point than diesel. On the other hand, it can be found in the literature a mention of some technical problems related to its use, such as the increase of $\mathrm{NO}_{x}$ gas emission compared with diesel, which should be examined with more caution.

Similarly alcohol fuels have been tested as an alternative fuels by many researches, among such alcohols are dimethyl ether and ethanol Dimethyl ether (DME) has been considered as an alternative fuel for compression ignition $(\mathrm{Cl})$ engines recently, because of its relative environmental cleanliness. Its unique auto-ignition qualities due to its very high cetane number could be best utilized by high pressure ignition of liquid DME directly into a cylinder. Therefore, many experimental and numerical investigations on engines fueled with DME at various engine operation conditions have been reported [8-11].

A blend of ethanol and diesel was a subject of research since the 1980s and it was shown that ethanol-diesel blends were technically acceptable for existing diesel engines, [12-14]. The relatively high cost of ethanol production at that time meant that its use could only be considered in case of fuel shortages. Recently, the economics have become much more favorable for the production of ethanol and it is able to compete with standard diesel. Consequently there has been renewed interest in the ethanol-diesel blends with particular emphasis on emissions reductions. This point, of increasing importance today, alone justifies the incorporation of ethanol into fuels.

The use of alternative fuels, in this case, must be studied. These alternative fuels can, still, be mixed with the diesel and in this way, reduce the demand on diesel oil and try to minimize the emissions of gases that contribute to the greenhouse effect. Experimental engine testing provides an invaluable means of investigating engine performance. However, measurements inside the cylinder can be invasive and complicated to setup and are only able to ascertain some properties at a few discrete points in the cylinder. 
In addition, engine alterations necessary to vary parameters may be extremely time consuming.

The need for faster, cleaner, and more fuel efficient engines has developed from society's desires and regulatory mandates. This poses a very complex problem for engine designers, since many of these goals are competing. The process is further complicated because engine processes are still not fully understood. In the pursuit of these goals, it is necessary to have as good understanding of engine phenomena. For diesel engines, the work in this area has not been as extensive as for spark ignition engines.

In response, several codes emerged as a companion to experimental work in engine design, these codes are capable of modeling transient, three dimensional, compressible, multiphase flows with chemical reactions by solving the mass, momentum, and energy equations These codes are used for the simulation of compressed engines that use pure diesel fuel. A brief review of such codes is presented by Ref. [15]. In this paper, an appropriate code will be selected and modified in order to allow for the simulation process when the engine run on ethanol-diesel blends and on di-methyl ether (DME)- diesel blends, which to the best of the author knowledge has not been carried out before.

\section{SIMULATION MODEL}

The theoretical models used in the case of internal combustion engines can be classified into two main groups viz., thermodynamic models and fluid dynamic models. Thermodynamic models are mainly based on the first law of thermodynamics and are used to analyze the performance characteristics of engines. Pressure, temperature and other required properties are evaluated with respect to crank angle or in other words with respect to time. The engine friction and heat transfer are taken into account using empirical equations obtained from experiments. These models are further classified into two groups namely single-zone models and multi-zone models. On the other hand, multi-zone models are also called computational fluid dynamics models. These are also applied for the simulation of combustion process in the internal combustion engines. They are based on the numerical calculation of mass, momentum, energy and species conservation equations in either one, two or three dimensions to follow the propagation of flame or combustion front within the engine combustion chamber.

Several software, which are based on the above models, were commercialized in order to be used for the simulation of compression engines, namely; ProRacing engine simulation, Virtual engine DYNO, ECFM-3Z ( three zone extended coherent flame model), Advisor (ADvanced Vehlcle SimulatOR) and DIESEL-RK Software etc., In this work the Diesel-RK software was used since its agreement with experimental data was very good as indicated in references [16], [17]and [18].

\section{DIESEL-RK SOFTWARE}

It is a multi-zone model of diesel sprays evolution and combustion, it takes into account: the shape of injection profile, including split injection; drop sizes; direction of 
each spray in the combustion chamber; the swirl intensity; the piston bowl shape. Evolution of wall surface flows generated by each spray depends on the spray and wall impingement angle and the swirl intensity. Interaction between near-wall flows (further named wall surface flows) generated by the adjacent sprays is taken into account. The method considers hitting of fuel on the cylinder head and liner surfaces. The evaporation rate in each zone is determined by Nusselt number for the diffusion process, the pressure and the temperature, including temperatures of different walls where a fuel spray gets. A parametric study of the swirl intensity effect has been performed and a good agreement with experimental data was obtained. The calculations results allow describing the phenomenon of increased fuel consumption with increase of swirl ratio over the optimum value. The model has been used for simulation of different engines performances.. The model does not require recalibration for different operating modes of a diesel engine.

The model takes into account the following main equations:

\section{Conservation of mass}

- The rate of change of mass within any open system is the net flux of mass across the system boundaries

$$
\frac{\mathrm{dm}}{\mathrm{dt}}=\sum_{\mathrm{j}} \dot{\mathbf{m}}_{\mathrm{j}}
$$

\section{Conservation of species}

- Equations tracking the evolution of species within the combustion chamber will be developed on a mass basis .

$$
\dot{\mathrm{Y}}_{\mathrm{i}}=\sum_{\mathrm{j}}\left(\frac{\dot{\mathrm{m}}_{\mathrm{j}}}{\mathrm{m}}\right)\left(\mathrm{Y}_{\mathrm{i}}^{\mathrm{j}}-\mathrm{Y}_{\mathrm{i}}^{\mathrm{cvl}}\right)+\frac{\Omega_{\mathrm{i}} \mathrm{W}_{\mathrm{mw}}}{\rho}
$$

where ' $m$ ' denotes the total mass within the control cylinder. The species equations are deduced from their multi-dimensional counterparts by neglecting species diffusion terms, consistent with the zero-dimensional assumption.

\section{Conservation of energy.}

- The generalized energy equation for an open thermodynamic system may be written as

$$
\underbrace{\frac{\mathrm{d}(\mathrm{mu})}{\mathrm{dt}}}_{\substack{\text { Internal } \\ \text { Energy }}}=\underbrace{-\mathrm{p} \frac{\mathrm{dV}}{\mathrm{dt}}}_{\substack{\text { Displacentent } \\ \text { Work }}}+\underbrace{\frac{\mathrm{dQ} \mathrm{ht}}{\mathrm{dt}}}_{\substack{\text { Heat } \\ \text { Transfer }}}+\underbrace{\sum_{\mathrm{j}} \dot{\mathbf{m}}_{\mathrm{j}} \mathrm{h}_{\mathbf{j}}}_{\substack{\text { Enthalpy } \\ \text { Flux }}}
$$

In this work, DIESEL-RK software was used for the calculation of the performance for compression ignition engine, when it is powered by different alternative fuels. This is obtained by calculation and a brief description of the operating of diesel engine such as temperature, pressure and heat released or transferred at each stroke or crank angle. It 
has to be noted that and to the best of the author knowledge, this software has never been used to simulate a diesel engine running on blends of ethanol-diesel and dimethy ether-diesel blends. Consequently, this model was modified to accept the properties of theses blends.

\section{MEDOLOGY}

The parameters, which were calculated in order to find the performance of the engine are: brake power, specific fuel consumption and the thermal efficiency. These parameters were calculated for each blend and at different engine speed. The engine used in this work has the specification shown in table 1. While properties of the different fuel blends are shown in table 2 .

\section{DISCUSSION OF RESULTS}

The obtained results, which were obtained under full engine load conditions, are presented in figures 1 through 11. The variation of engine torque with speed for various fuel blends is indicated in figures 1 and 2 . It may be seen that, and as expected from theory, the engine torque increases with speed to a maximum value, beyond which it starts to decrease with speed. Further, as indicated in these two figures and at any fixed value of speed, the engine torque decreases with increasing the amount of either ethanol or tether in the fuel blend.

Figures 3 and 4 show the variation of the engine power with speed for ethanol-diesel and ether-diesel blends respectively. As expected and as a general trend, initially the engine power increases with a speed to a maximum value at a speed engine of 3500 rpm, beyond which the power remains constant, however it is expected to decrease as speed further increases. Further, it may be noticed that the power produced decreases with the percentage amount of alcohol added. This is due to the fact that the heat content of both ethanol and ether are lower than that of pure diesel, and hence the blends formed are of heating values than that of the pure diesel. Furthermore and due to the fact that both ether and ethanol have lower cetane values that pure diesel, it is expected that the blends fuel will cause a drop in the engine power output. These results are in agreement with the experimental results outlined in Ref. [19]

Figures 4 and 6 show the variation of the specific fuel consumption with speed for ethanol-diesel and ether-diesel blends respectively. It is observed that for all the ethanol-diesel fuel and ether-diesel blends, the specific fuel consumption is a little higher than the corresponding diesel fuel case, with the increase being higher the higher the percentage of ethanol and ether in the blend. This is the expected behavior due to the lower calorific value of the ethanol compared to that for the neat diesel fuel. Also this is in agreement with the experimental results indicated in Ref.[20].

The engine thermal efficiency for the neat diesel fuel and the various percentages of the ethanol and ether in their blends with diesel fuel is presented in figures 7 and 8 respectively. Noting that the brake thermal efficiency is simply the inverse of the product of the specific fuel consumption and the lower calorific value of the fuel, the results of this figure can be explained. It is observed that for both the ethanol-diesel fuel blends and those of ether-diesel blends, the brake thermal efficiency is slightly 
higher than that for the corresponding neat diesel fuel case, with the increase being higher the higher the percentage of ethanol or ether in the blends. This means that the increase of brake specific fuel consumption for both the ethanol-diesel blends and the ether-diesl blends is lower than the corresponding decrease of the lower calorific value of the blends. This is in agreement with the experimental results presented in Ref. [21].

Further, from these thermal efficiency figures it may be noted that the engine is of maximum thermal efficiency when $15 \%$ of ethanol-diesel blend and $15 \%$ ether-diesel blends were used as fuel for the engine. Consequently the performance of the engine when powered by these two types of blends will be selected for further investigation.

Figure 9 indicates that the power produced by the engine over the speed range in this work is maximum when pure diesel is used to run engine, while the $15 \%$ ethanoldiesel blend produces the minimum power output. This is, and as discussed above due to the fact that the heating value of diesel fuel is of maximum value followed by that of ether and ethanol. Further figure 10 shows that the engine is of minimum specific fuel consumption ( minimum amount of fuel is consumed to produce one kW.hr) when pure diesel is used, while it is maximum when the engine is powered by $15 \%$ ethanol-diesel blend

Finally and as expected the engine is of highest thermal efficiency when it is powered by the $15 \%$ ethanol-diesel blend, while the engine is of minimum thermal efficiency when it is powered by pure diesel fuel, as shown in figure 11.

\section{CONCLUSIONS}

In this work a four strokes compression engine was simulated using a software. The simulation was performed in order to find the performance of the engine when it is powered by different types of fuels. The followings may be concluded from this study:

1. The addition of both ethanol and ether to diesel fuel will cause a drop in the power output of the engine and hence the specific fuel consumption will increase, while the thermal efficiency will increase

2. The addition of both ethanol and ether will have almost same effect on the performance of the engine.

\section{REFERENCES}

[1] N. Usta, An experimental study on performance and exhaust emissions of a diesel engine fuelled with tobacco seed oil methyl ester, Energy Conversion Manage 46, pp. 2373-2386. (2005)

[2] O.M.I. Nwafor, Emission characteristics of diesel engine running on vegetable oil with elevated fuel inlet temperature, Biomass Bioenergy 27, pp. 507-511. (2004), 
[3] X. Li, X. Qiao, L. Zhang, J. Fang, Z. Huang and H. Xia, Combustion and emission characteristics of a two-stroke diesel engine operating on alcohol, Renewable Energy 30 pp. 2075-2084 (2005)

[4] C. Carraretto, A. Macor, A. Mirandola, A. Stoppato and S. Tonon, Biodiesel as alternative fuel: Experimental analysis and energetic evaluations, Energy 29, pp. 2195-2211.(2004)

[5] S. Kalligeros, F. Zannikos, S. Stournas, E. Lois, G. Anastopoulos, Ch. Teas and F. Sakellaropoulos, An investigation of using biodiesel/marine diesel blends on the performance of a stationary diesel engine, Biomass Bioenergy 24, pp. 141-149. (2003)

[6] S. Puhan, N. Vedaraman, B.V.B. Ram, G. Sankarnarayanan and K. Jeychandran, Mahua oil (madhuca indica seed oil) methyl ester as biodiesel-preparation and emission characteristics, Biomass Bioenergy 28 .pp. 87-93. (2005)

[7] A.S. Ramadhas, C. Muraleedharan and S. Jayaraj, Performance and emission evaluation of a diesel engine fueled with methyl esters of rubber seed oil, Renewable Energy 30 pp. 1789-1800. (2005)

[8] Denis G, Herwig O, Daniel S, Eddie S, Marc AW, The performance of a heavy duty diesel engine with a production feasible DME injection system. SAE Tech paper, 2001-01-3629; (2001).

[9] Shuichi K, Chen CL, Shuichi K, Mitsuharu O, Alam M, Rhee KT, Direct injection diesel engine operated with propane-DME blend fuel, SAE Tech paper, 982536;(1998)

[10] Shuichi K, Mitsuharu O, Tomoya M, DME fuel blends for low emission directinjection diesel engines. SAE Tech paper, 2000-01-2004; (2000.)

[11] Sato Y, Noda A, Sakamoto T, Goto Y, Performance and emission characteristics of a DI diesel engine operated on dimethyl ether applying EGR with supercharging. SAE Tech paper, 2000-01-1809; (2000).

[12] Bilgin A, Durgum O, and Sahin Z, The effect of diesel ethanol blends on dieselmengine performance, Energy sources 24 pp. 431-440.(2002)

[13] Ajav, E., Singh,B. and Bhattacharya, T., Performance os a stationary diesel engine using vaporized ethanol as a supplementary fuel. Biomass 15,pp.493-502.(1998)

[14] Ecklund EE, Bectold RL, Timbario TJ. State-of-the-Art Report on Use of Alcohols in Diesel Engines. SAE Technical Paper Series 840118. International Congress and Exposition, Detroit, Michigan; (1994).

[15] A.S. Ramadhas, S. Jayaraj and C. Muraleedharan, Theoretical modeling and experimental studies on biodiesel-fueled engine, Renewable Energy 31 p.18131826.(2006) 
[16] A.S. Kuleshov: "Multi-Zone DI Diesel Spray Combustion Model and its application for Matching the Injector Design with Piston Bowl Shape", SAE Paper No 2007-011908,( 2007).

[17] A.S. Kuleshov: "Use of Multi-Zone DI Diesel Spray Combustion Model for Simulation and Optimization of Performance and Emissions of Engines with Multiple Injection ", SAE Paper No. 2006-01-1385,( 2006)

[18] A.S. Kuleshov : "Model for predicting air-fuel mixing, combustion and emissions in DI diesel engines over whole operating range", SAE Paper No. 2005-01-2119, (2005).

[19] Eliana Weber de Menezes, Rosa^ngela da Silva, Renato Cataluña *, Ricardo J.C. Ortega. "Effect of ethers and ether/ethanol additives on the physicochemical properties of diesel fuel and on engine tests." Fuel 85 815-822.(2006)

[20] C.D. Rakopoulos, K.A. Antonopoulos and D.C. Rakopoulos. "Experimental heat release analysis and emissions of a HSDI diesel engine fueled with ethanol diesel fuel blends ." Energy Volume 32, Issue 10, October, Pages 1791-1808 .(2007)

[21] E Menezes, R. Silva, R. Catalu and R. Ortega. "Effect of ethers and ether/ethanol additives on the physicochemical properties of diesel fuel and on engine tests." Fuel 85 815-822(2006)

Tables:

Table 1. Engine specification

\begin{tabular}{|c|c|}
\hline Type & Automotive 30 Test Bed \\
\hline Bore & $72.25 \mathrm{~mm}$ \\
\hline Stroke & $88.18 \mathrm{~mm}$ \\
\hline Number of Cylinder & Four Cylinder \\
\hline Type of Injection & Direct Injection \\
\hline Type of Cooling & Water cooled \\
\hline Swept Volume & $1450 \mathrm{cc}$ \\
\hline Compression Ratio & 21.5 \\
\hline Intake Valve Diameter & $34.51 \mathrm{~mm}$ \\
\hline Exhaust Valve Diameter & $28.49 \mathrm{~mm}$ \\
\hline Connected Rod Length & $155.8 \mathrm{~mm}$ \\
\hline Maximum torque & $80 \mathrm{~N} . \mathrm{m}$ \\
\hline Maximum power & $30 \mathrm{~kW}$ \\
\hline
\end{tabular}


Table 2. Properties of the different fuel blends

\begin{tabular}{|c|c|c|c|}
\hline Fuel & Density $\left(\mathrm{kg} / \mathrm{m}^{3}\right)$ & $\begin{array}{c}\text { Cetane } \\
\text { number }\end{array}$ & $\begin{array}{c}\text { Calorific } \\
\text { value }(\mathrm{kJ} / \mathrm{kg})\end{array}$ \\
\hline Diesel & 837 & 50 & 43000 \\
\hline Ethanol & 788 & $5-8$ & 26800 \\
\hline Ether & 670 & $55-60$ & 28900 \\
\hline E-5 & 835 & 48 & 42000 \\
\hline E-10 & 832 & 46 & 41400 \\
\hline E15 & 830 & 43 & 40600 \\
\hline Ether-5 & 812 & 56 & 42500 \\
\hline Ether-10 & 820 & 57 & 42000 \\
\hline Ether-15 & 829 & 58 & 40800 \\
\hline
\end{tabular}

Figures:

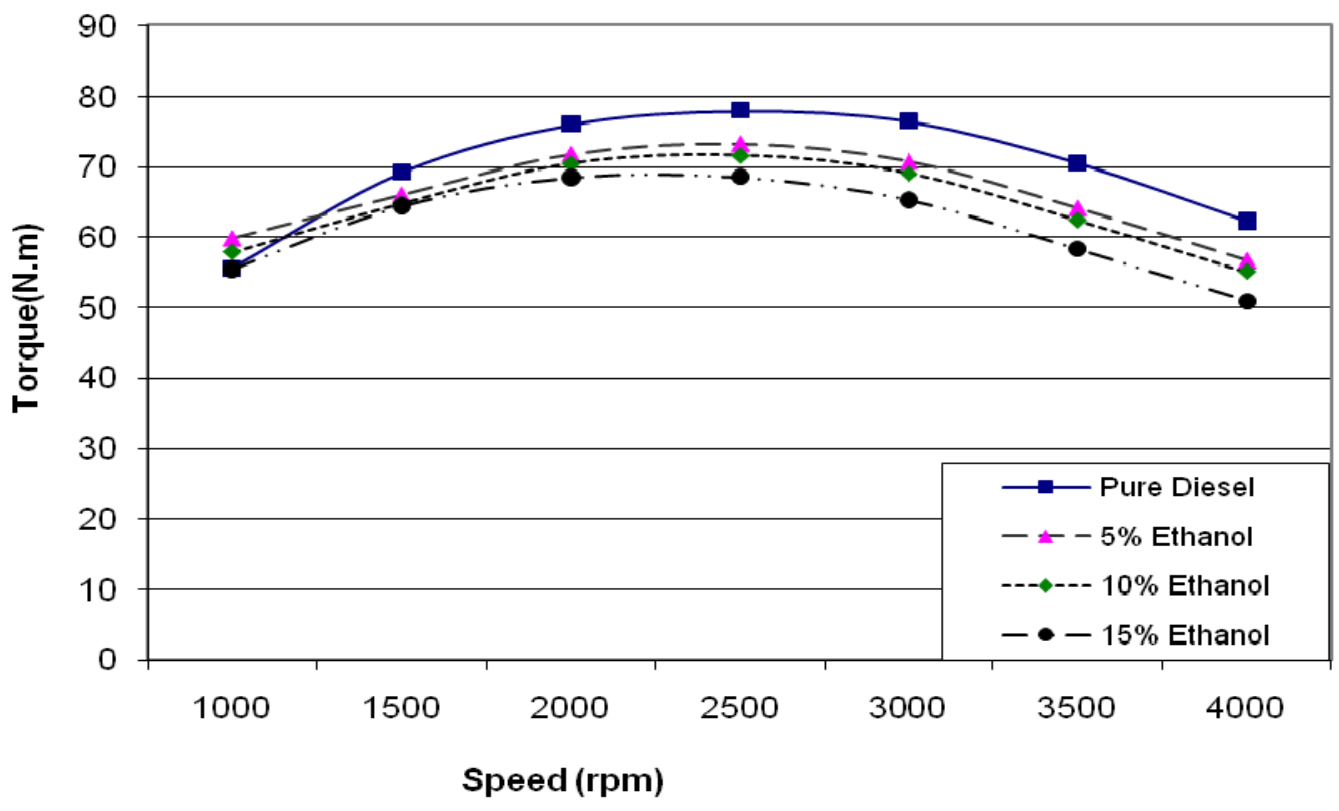

Figure 1. Variation of engine torque with speed for different ethanol-diesel blends 


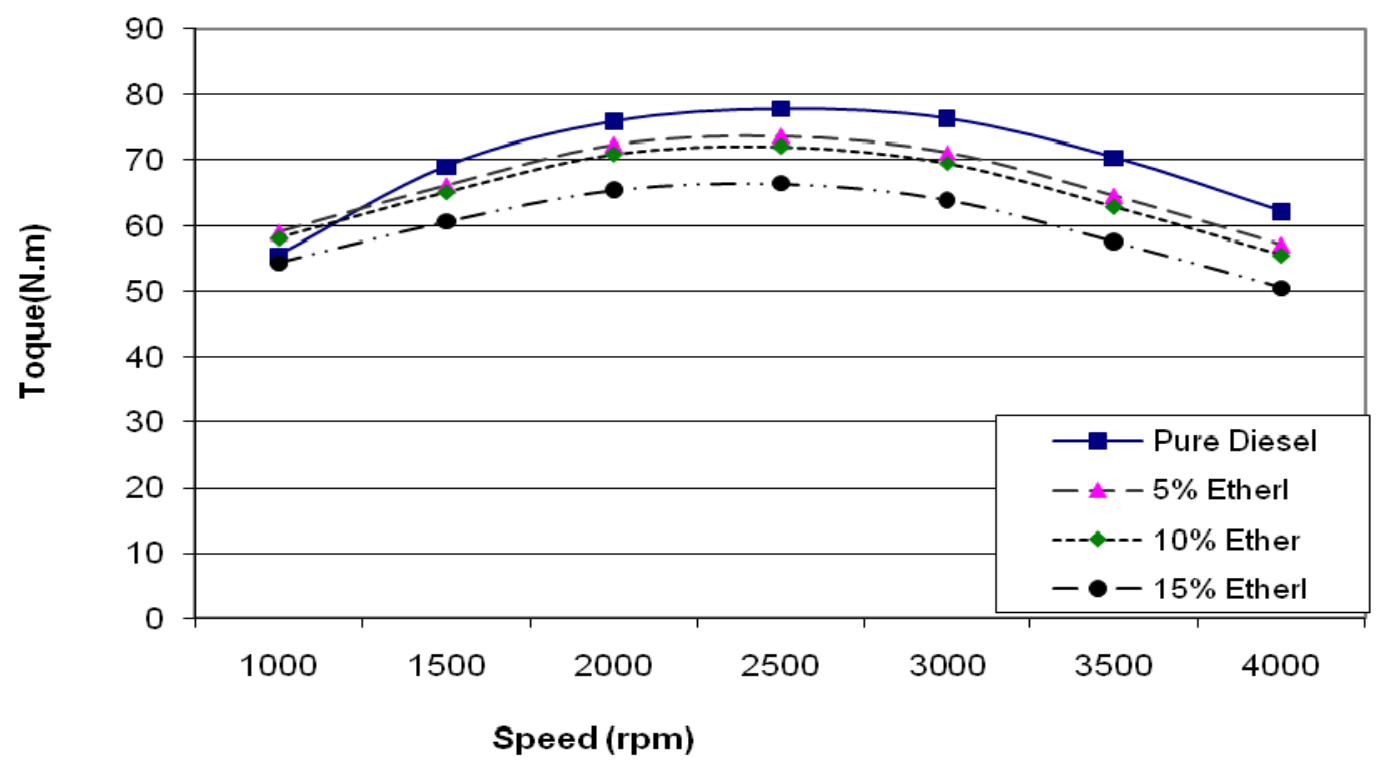

Figure 2. Variation of engine torque with speed for different ether-diesel blends

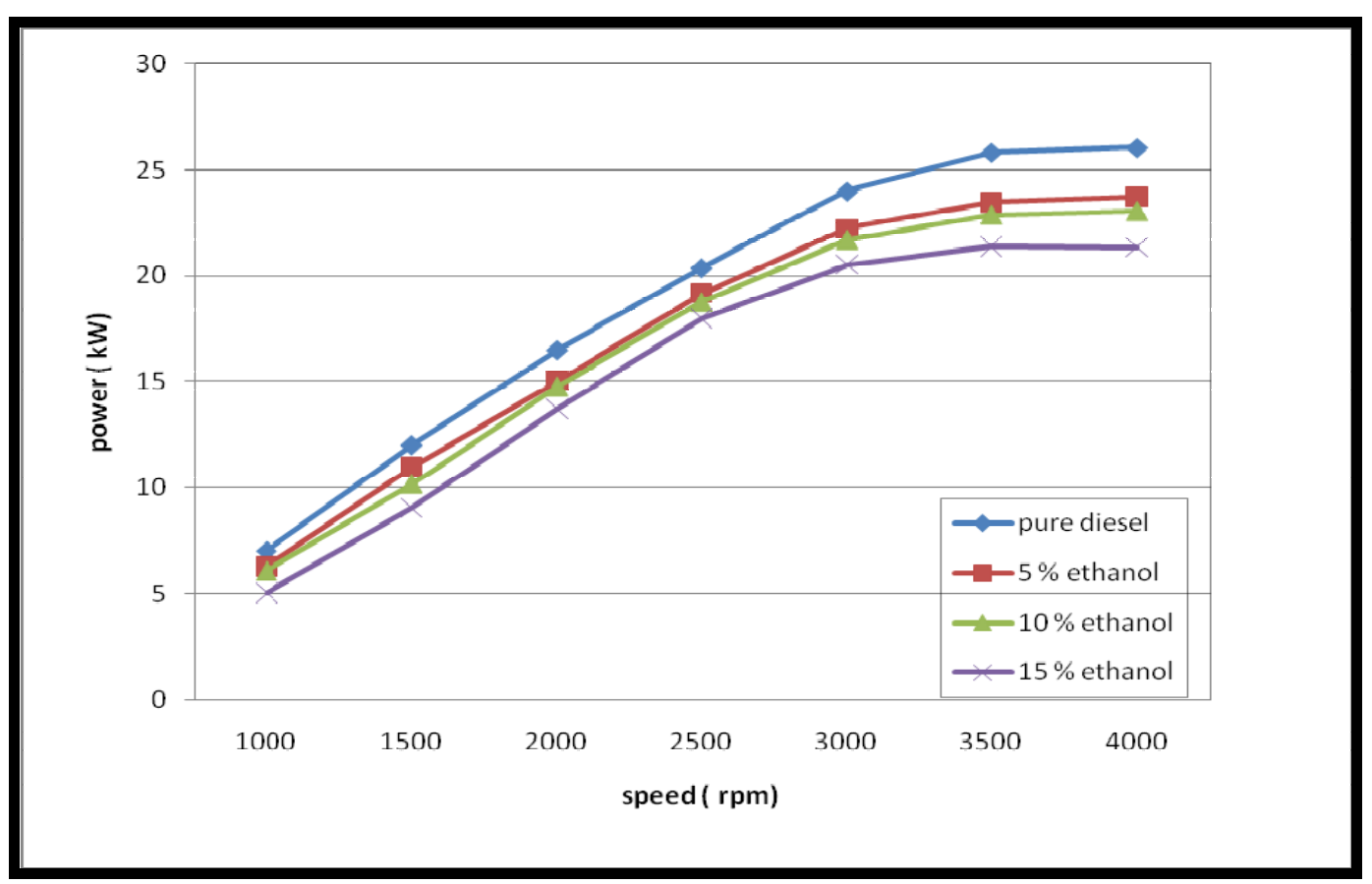

Figure 3. Variation of engine power with speed for different ethanol-diesel blends 


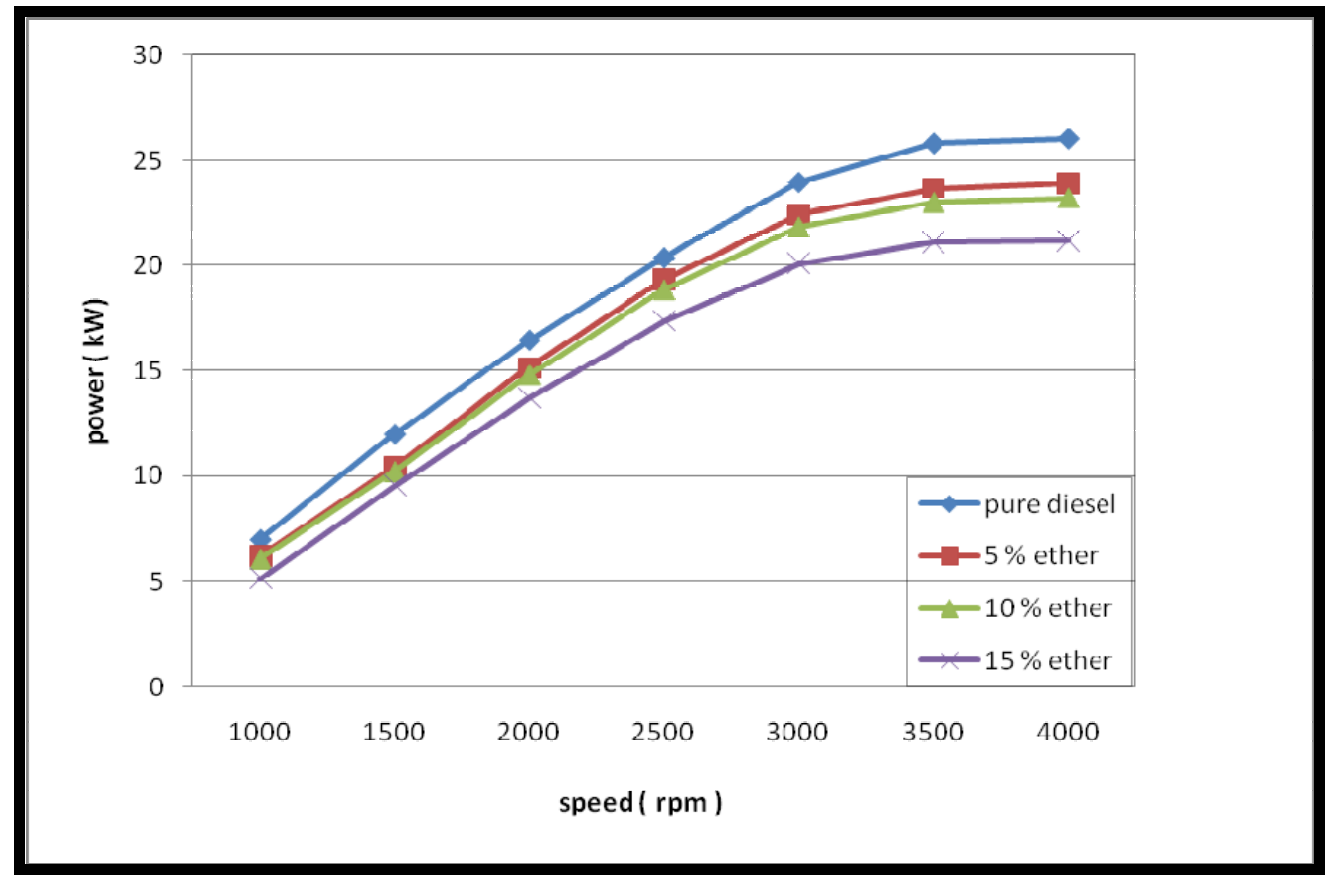

Figure 4. Variation of engine power with speed for different ether-diesel blends

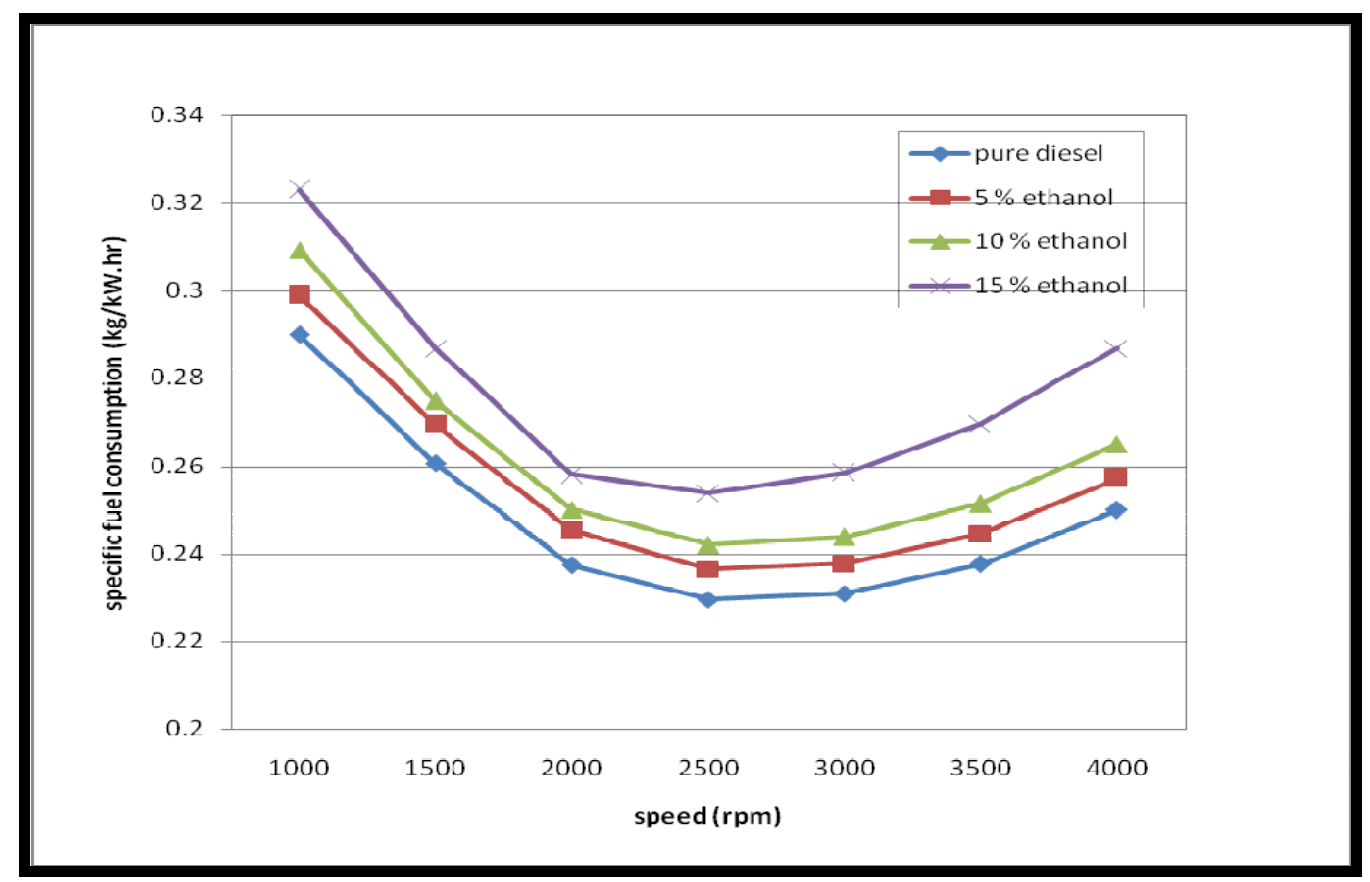

Figure 5. Variation of engine specific fuel consumption with speed for different ethanoldiesel blends. 


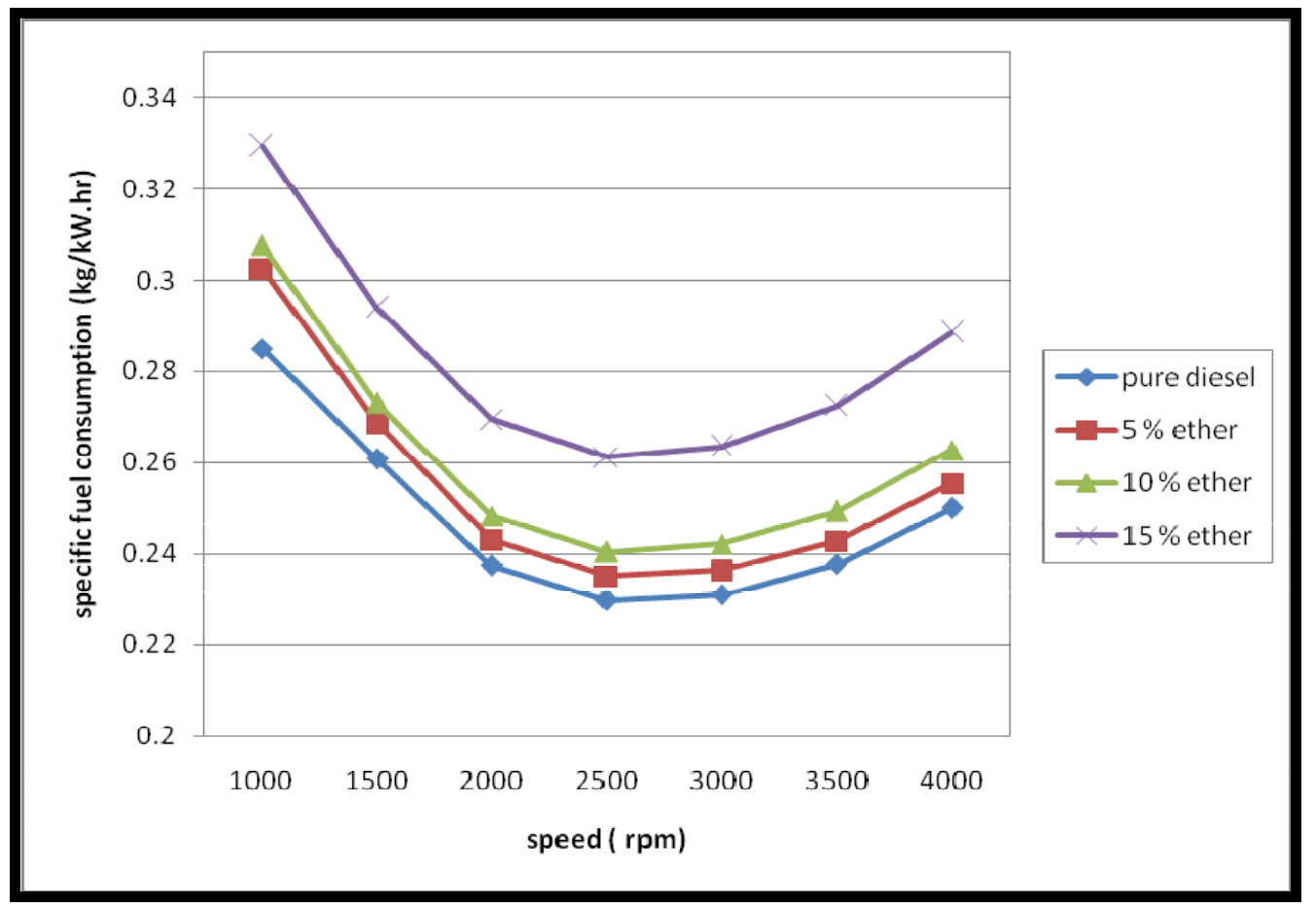

Figure 6. Variation of engine specific fuel consumption with speed for different etherdiesel blends.

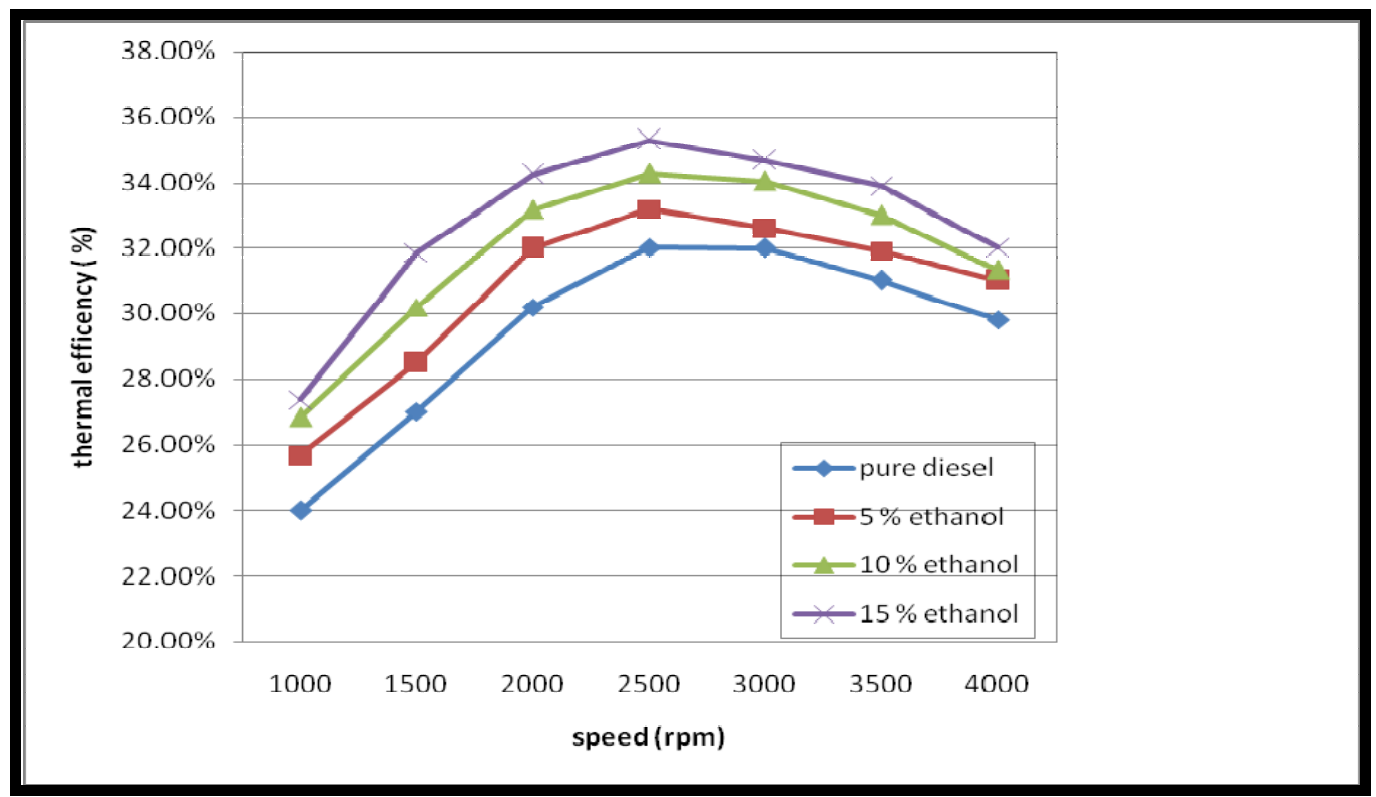

Figure 7. Variation of engine thermal efficiency with speed for different ethanol-diesel blends. 


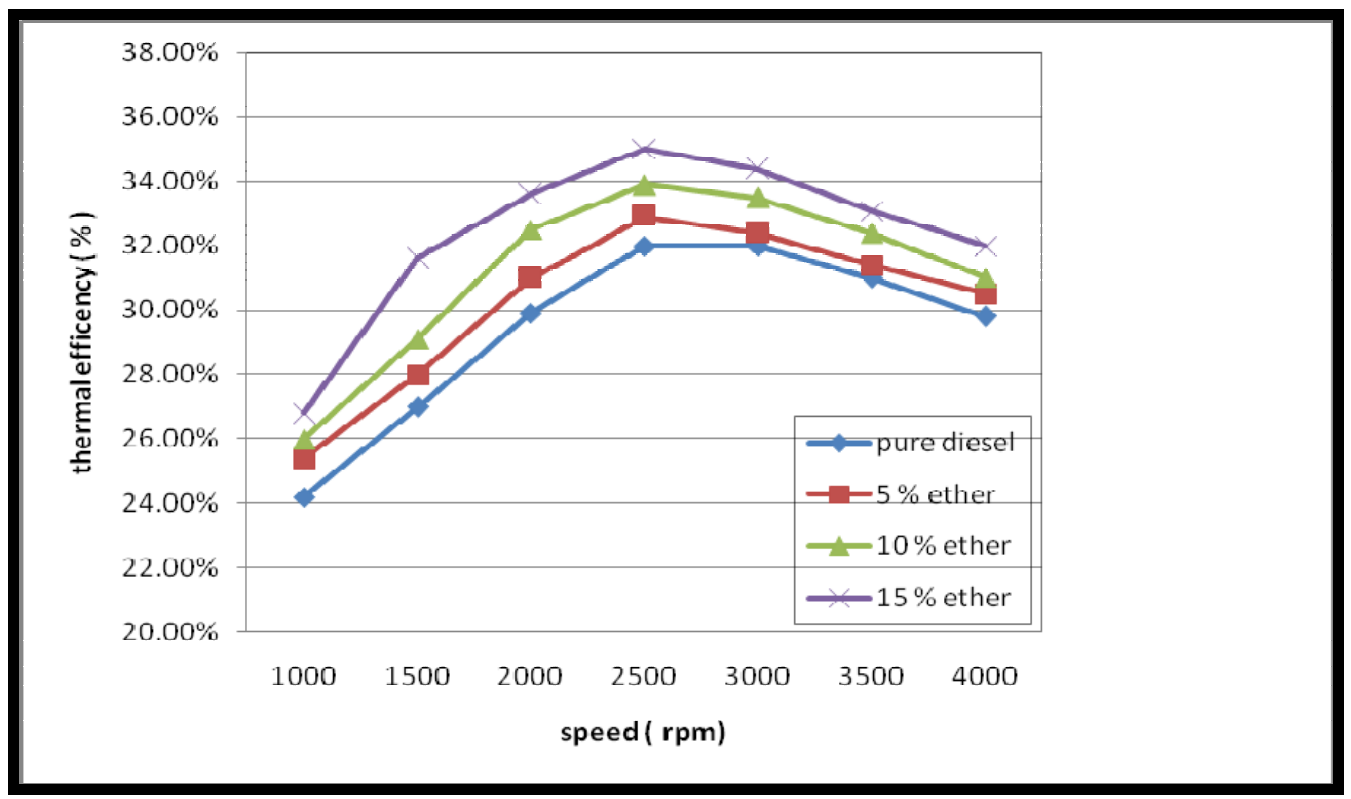

Figure 8. Variation of engine thermal efficiency with speed for different ether-diesel blends.

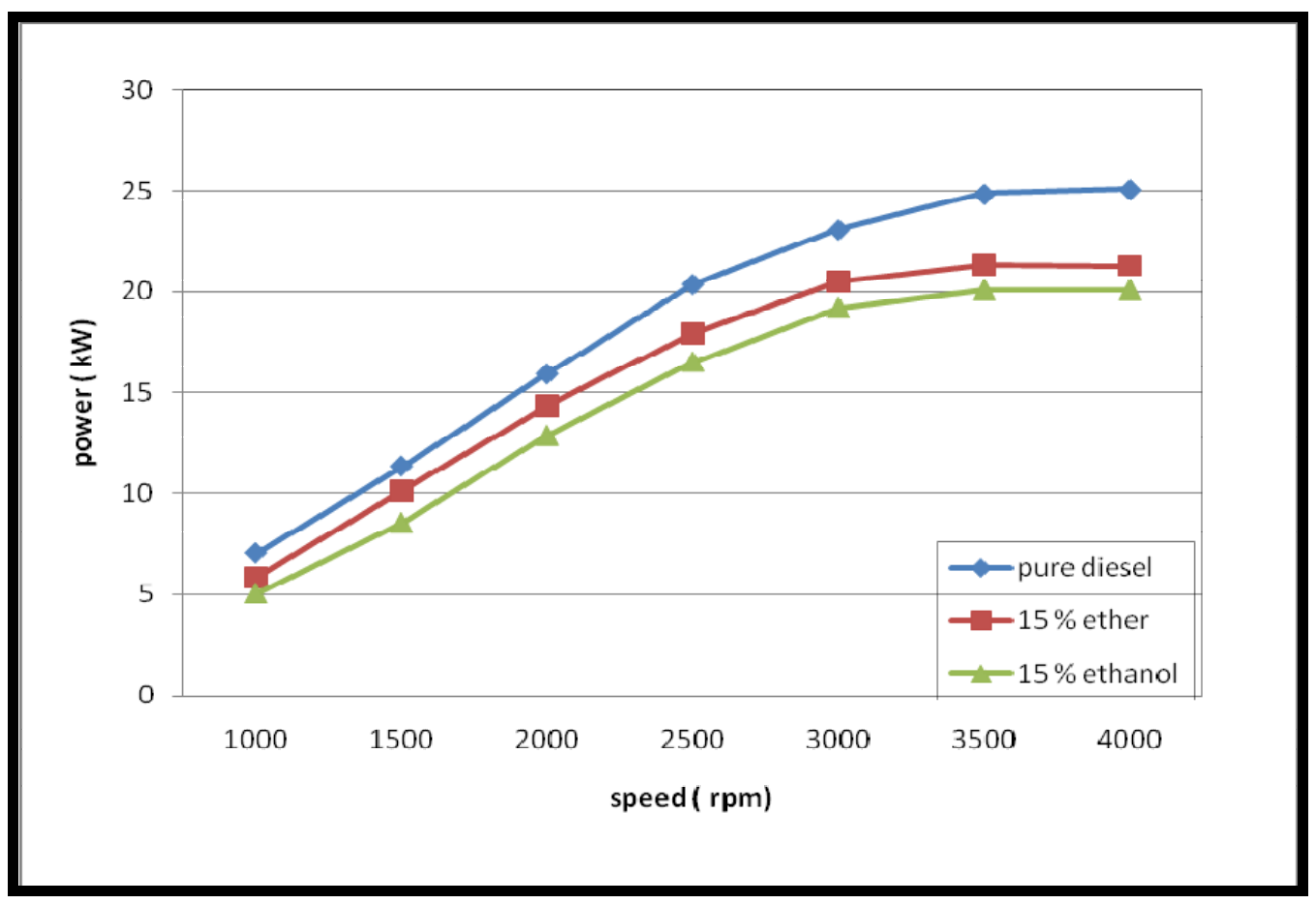

Figure 9. Variation of engine power with speed for different fuel types. 


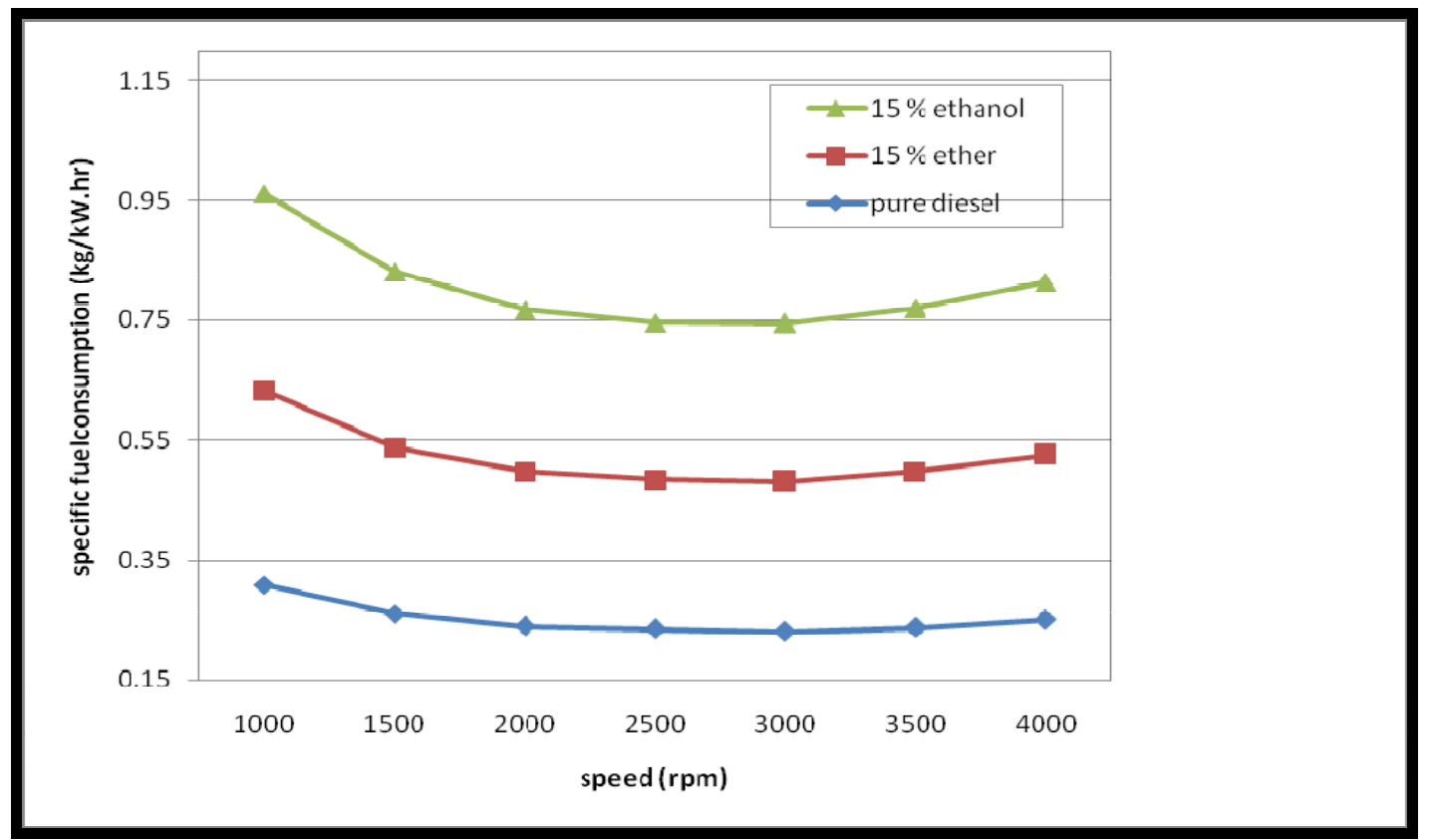

Figure 10. Variation of engine specific fuel consumption with speed for different fuel types.

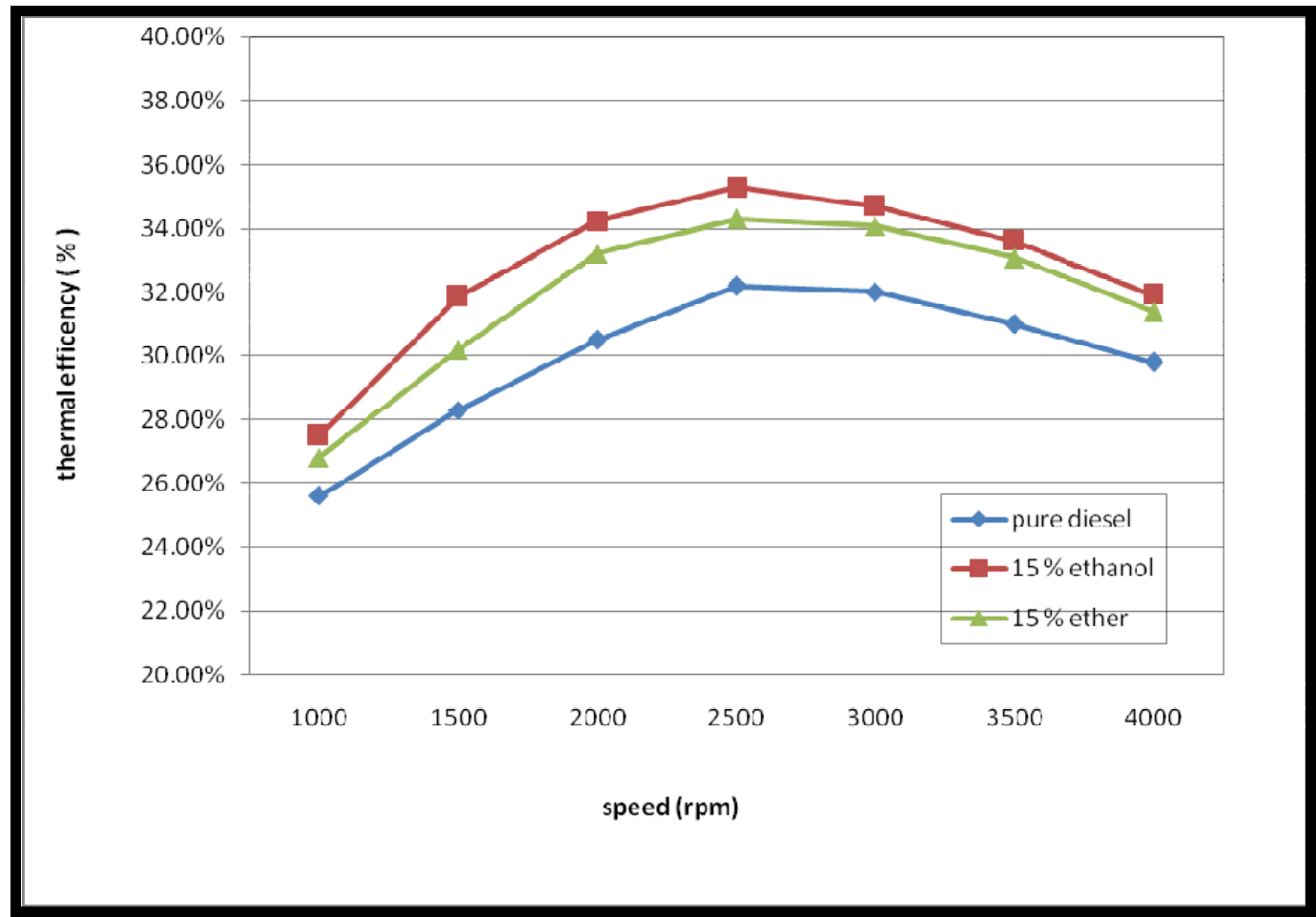

Figure 11.Variation of engine thermal efficiency with speed for different fuel types. 